\title{
BMJ Open Handover training for medical students: a controlled educational trial of a pilot curriculum in Germany
}

\author{
Laura Thaeter, ${ }^{1,2}$ Hanna Schröder, ${ }^{1,2}$ Lina Henze, ${ }^{2}$ Jennifer Butte, ${ }^{1}$ Patrick Henn, ${ }^{3}$ \\ Rolf Rossaint, ${ }^{1}$ Saša Sopka ${ }^{1,2}$
}

To cite: Thaeter L, Schröder $\mathrm{H}$ Henze L, et al. Handover training for medical students: a controlled educational trial of a pilot curriculum in Germany. BMJ Open 2018;8:e021202. doi:10.1136/ bmjopen-2017-021202

- Prepublication history and additional material for this paper are available online. To view, please visit the journal online (http://dx.doi.org/10.1136/ bmjopen-2017-021202)

LT and HS contributed equally.

Received 18 December 2017 Revised 29 June 2018 Accepted 17 July 2018

A) Check for updates

(C) Author(s) (or their employer(s)) 2018. Re-use permitted under CC BY-NC. No commercial re-use. See rights and permissions. Published by BMJ.

${ }^{1}$ Anesthesiology Clinic, University Hospital Aachen, Medical Faculty, RWTH Aachen University, Aachen, Germany

${ }^{2}$ Aachen Interdisciplinary Training Center for Medical Education, Medical Faculty, RWTH Aachen University, Aachen, Germany

${ }^{3}$ School of Medicine, University College Cork, Cork, Ireland

Correspondence to

Dr Laura Thaeter;

Ithaeter@ukaachen.de

\section{ABSTRACT}

Objective The aim of this study was to implement and evaluate a newly developed standardised handover curriculum for medical students. We sought to assess its effect on students' awareness, confidence and knowledge regarding handover.

Design A controlled educational research study.

Setting The pilot handover training curriculum was integrated into a curriculum led by the Departments of Anesthesiology and Intensive Care (Al) at the University Hospital. It consisted of three modules integrated into a 4-week course of Al. Multiple types of handover settings namely end-of-shift, operating room/postanaesthesia recovery unit, intensive care unit, telephone and discharge were addressed.

Participants A total of $n=147$ fourth-year medical students participated in this study, who received either the current standard existing curriculum (no teaching of handover, $n=78$ ) or the curriculum that incorporated the pilot handover training $(n=69)$.

Outcome measures Paper-based questionnaires regarding attitude, confidence and knowledge towards handover and patient safety were used for pre-assessment and post-assessment.

Results Students showed a significant increase in knowledge $(p<0.01)$ and self-confidence for the use of standardised handover tools $(p<0.01)$ as well as accurate handover performance $(p<0.01)$ among the pilot group. Conclusion We implemented and evaluated a pilot curriculum for undergraduate handover training. Students displayed a significant increase in knowledge and selfconfidence for the use of standardised handover tools and accuracy in handover performance. Further studies should evaluate whether the observed effect is sustained across time and is associated with patient benefit.

\section{INTRODUCTION}

The accurate handover of a patient is crucial for the patient's safety and impacts significantly on the quality of treatment. ${ }^{1}$ Communication failures are one of the top three root causes for adverse events, and miscommunication contributes to about $80 \%$ of these. ${ }^{2}$

Poor handovers have an impact on both the patient's health and on the healthcare

\section{Strengths and limitations of this study}

- This work presents a first controlled educational cohort study in Germany comparing undergraduate medical student's awareness, confidence and knowledge towards patient handover between the current standard anaesthesiology and intensive care (Al) curriculum versus a pilot Al curriculum incorporating handover training.

- A first German open-source handover curriculum was developed according to Kern's Principles of Curriculum Development and was integrated into a 4-week course of Al.

- The pilot curriculum consisted of three training modules and used practical training to address handover within different clinical scenarios.

- Two study arms measured the effects of the pilot intervention regarding awareness, confidence and knowledge towards handover in the context of patient safety but did not include the assessment of practical performance.

- The presented data are limited by subjective ratings in standardised questionnaires.

system. They may cause significant adverse or even life-threatening events, including delay in diagnosis and treatment leading to prolonged hospitalisation, increased costs and patient complaints. ${ }^{3}$ In anaesthesiology and intensive care (AI), and emergency medicine, a direct relationship between qualitative inappropriate handover and adverse events has been described. ${ }^{45}$ Every intraoperative anaesthesiology handover increases the risk of complications by $8 \%{ }^{6}$ The National Patient Safety Agency defines clinical handover 'as the transfer of professional responsibility and accountability for some or all aspects of care for a patient, or group of patients, to another person or professional group on a temporary or permanent basis'.

The Joint Commission ${ }^{1}$ and the World Health Organization ${ }^{8}$ both recommend structured communication in healthcare. 
The European Union provides similar recommendations on 'Patient Safety Education and Training' through the European Network for Patient Safety, and the Patient Safety and Quality of Care Working Group gives examples of good practice in education and training of patient safety in Europe ${ }^{10}$ In Germany, the Working Group for Education and Training by the German Coalition for Patient Safety has formulated learning goals for patient safety ${ }^{11}$ while the German Association for Medical Education also works on the structured implementation of patient safety curricula. ${ }^{12}$

While all these groups discuss patient safety, in Germany, as well as in Europe, there are very little requirements for medical curricula to address patient handover in medical education, and teaching of handover is variable. ${ }^{1314}$ The WHO in their Patient Safety Curriculum for Medical Students $2009^{8}$ and Multi-professional Edition $2011^{15}$ address handover training in the medical field. However, those recommendations and approaches do not specifically address patient handover and its relevance and importance commencing from undergraduate medical education. Recently, the European Council of Resuscitation and the German Society of Anesthesiology and Intensive Care Medicine have started to recommend structured communication using (I) SBAR, (Identify), Situation, Background, Assessment and Recommendation. ${ }^{16} 17$ Despite this, newly qualified doctors feel unprepared for handover, and handover training remains problematic. ${ }^{18-20}$

Thus, on a European level, handover training for medical students is neither standardised nor extensively implemented. However, the advent of work schedule directives has resulted in an increased number of shift changes with a consequent increase in the number of handovers. Teaching handover at an undergraduate level could foster young doctors to feel more prepared and have positive impact on patient safety. Over the past several years, the call for a change in medical education regarding patient safety and the training needs for European medical students have been evaluated. ${ }^{82} 22$ Data regarding the best practice of handover as well as curriculum development and effects on patient outcomes are limited. ${ }^{1323}$ Most studies focus on handover tools in the inpatient setting in order to improve patient handover efficiency and completeness. ${ }^{23}$ The evaluation of educational interventions for teaching handover in undergraduate medical education shows great heterogeneity with methodology and measured outcomes, with most studies coming from the USA. ${ }^{1424}$ A few studies have investigated single handover training methods but rarely assessed the whole curriculum. ${ }^{142425}$

The aim of this study was to implement and evaluate a newly developed standardised handover training curriculum for medical students in Germany. The main objective was to assess whether the training of handover skills resulted in a change in awareness, confidence and knowledge of medical students towards handover in AI and emergency medicine settings.

\section{METHODS AND MATERIALS \\ Participants}

One hundred and forty-seven medical students from the Medical School of RWTH Aachen University, Germany, 
participated. They were in their fourth year, taking part in the clinical clerkship in AI and emergency medicine (academic year 2014-2015). The modular curriculum in this school does not separate into preclinical and clinical years of education, but it consists of an organ-based integrated curriculum. By their fourth year, students have had previous clinical experience in clerkships and rotations. Participation in the study was optional and written consent was obtained. All participants were informed that their performance would be evaluated and used for scientific purposes. Independent from the project and pilot study, subjects were randomly assigned to groups of 6-8 students by the Study Board for Medical Education. Due to the limited project runtime, a random allocation of these groups to the study arms could not be realised.

\section{Patient and public involvement}

No patients were involved in this study. Study participants were offered feedback of the study results and will be informed of this publication.

\section{Study design}

The Aachen Interdisciplinary Training Centre for Medical Education participated in the European Union-funded PATIENT-project that developed and implemented a handover curriculum (figure 1). ${ }^{26}$ The primary objective of the PATIENT-project (The PATIENT-project: 'Improving the continuity of patient care through novel teaching and learning facilities for handover procedures in medical higher education') was the implementation of the handover study module for undergraduate medical students on a European scale.

In the 2014-2015 academic year, selected modules of the handover curriculum were integrated into an already existing course led by the Departments of AI within the topics of anesthesiology, intensive care- and emergency care medicine at the University Hospital in Aachen, Germany. ${ }^{27}$ Students underwent the course as part of their curriculum (pilot or control) irrespective of whether or not they agreed to participate in the study.

The pilot concept was conducted as an integrated educational research study in order to compare two groups. Students of the control group received the existing curriculum without the handover teaching. Students of the intervention group received standardised handover training in the pilot curriculum. To compare the two study arms and measure the effects of the pilot intervention, students of both groups received a precourse and postcourse paper-based questionnaire regarding awareness, confidence and knowledge towards handover and patient safety. The study protocol was exempted by the institutional Ethics Committee.

\section{Curriculum development and implementation}

Curriculum development was conducted according to Kern's Principles of Curriculum Development. ${ }^{28}$ This development process is described in the following six steps:
1. Local identification of needs and problems: A training-needs analysis (PATIENT-project work package 2) was conducted via a cross-sectional online survey among medical students and teaching staff at three European universities, including the RWTH Aachen University. ${ }^{29}$ The complete results of the local training-needs analysis are currently under review for publication and will be fully available soon.

2. Selecting learning goals and objectives according to the learner's needs: The method of group concept mapping was applied to define relevant learning objectives. The original data have already been published. ${ }^{22}$ Three modules of the curriculum were defined: risk and error management, effective communication and simulation.

3. Defining educational strategies: Diverse training methods were tested and applied according to the local results of the needs analysis. Emphasis was put on interactive seminars, practical case-based trainings and simulation, online module and pocket cards. The content of the training modules covered the theoretical background on patient safety and the relevance of handover, introduction of standardised handover protocols and mnemonics (such as I-PASS, Illness Severity, Patient Summery, Action List, Situation Awareness \& Contingency Planning, Synthesis by Receiver; ISBAR; MIST, Meachnism, Injury, Signs \& Symptoms, Therapy; ABCDE, Airway, Breathing, Circulation, Disability, Exposure; SAMPLER, Signs/Symptoms, Allergies, Medications, Past medical history, Last oral intake, Events leading up to present illness/injury, Risk factors), as well as practical exercises (eg, role plays, basic simulation cases). Different clinical contexts were provided (emergency medicine, anesthesiology and intensive care medicine) and various handover scenarios such as patient admission, transfer, shift change or patient discharge were considered during the training. Different learning styles were met by applying different training methods. Looking at handover from different perspectives of communication, risks and error management, patient safety, interprofessionalism and teamwork promoted a broad insight to the topic.

4. Assessment: Attitudes, confidence and knowledge towards handover and patient safety were planned with pre-post-design questionnaires. For clarity reasons, it is described in the following section of measurements and data acquisition.

5. Implementation (according to existing resources): For this study, the curriculum was adapted to meet local needs as well as to be integrated into the teaching and training led by the Departments of Anaesthesiology and Intensive Care Medicine. The adapted pilot curriculum (figure 1) consisted of three modules (1-2 hours each) and was integrated into an existing 4-week course of AI. The modules were delivered as an interactive seminar (unit 1) and a practical handover training (unit 2) accompanied by a longitudinal online module (unit 3). Open discussions were possible via the online module 
on the e-learning platform. The online supplementary file further explains the contents of the different training units. The multiple scenarios of handover such as end-of-shift, transfer of operating room to postanaesthesia recovery unit or intensive care unit (ICU), telephone handover and patient discharge to follow-up treatment were integrated into already existing parts of the 4-week AI course.

6. Evaluation: Standardised course ratings were obtained as it is usual for all courses in the medical school.

\section{Measurements and data acquisitions}

\section{Preassessment/postassessment questionnaires}

Students of both groups, control and intervention, were tested with the same paper-based questionnaire (25-28 items) on a 6-point Likert scale regarding awareness, confidence and knowledge towards handover and patient safety. Points 5 and 6 on the Likert scale ( $1=$ 'fully disagree' to $6=$ 'fully agree') were counted as agreement. All items in this section were carried over from the PATIENT-projects' training-needs analysis. The items were generated through a multistep approach, including literature review, interviews and expert consultation and were therefore considered to be representative of construct and content validity. In a pretest, it was also checked for reliability. ${ }^{29}$

Knowledge was measured by nine multiple choice questions concerning patient safety and handover that were created by the training centre's staff experienced in teaching and assessment.

The course rating was obtained through the 6-point German grading scale ( $1=$ 'very good' to $6=$ "insufficient') which is commonly used to evaluate educational courses.

\section{Outcomes}

Outcome parameters, defined as endpoints, were changes in awareness, confidence and knowledge after the handover teaching intervention compared with pre-course assessments.

\section{Statistical analysis}

All statistical analyses were performed using the Statistical Package for the Social Sciences software (IBM Released 2015. IBM SPSS Statistics for Windows, V.23.0). Continuous variables were summarised by the means and corresponding SD, while categorical data were presented as percentages. In terms of questionnaire outcome variables (6-point Likert scale), means and SD were reported. Because of the distribution characteristics of the questionnaire values, appropriate non-parametric tests (Wilcoxon, Mann-Whitney) were used to analyse between-groups and in-group differences. All tests were two-sided and were assessed at the $5 \%$ significance level. Due to the exploratory nature of the parallel study hypotheses, we did not adjust the significance level to account for multiple tests.

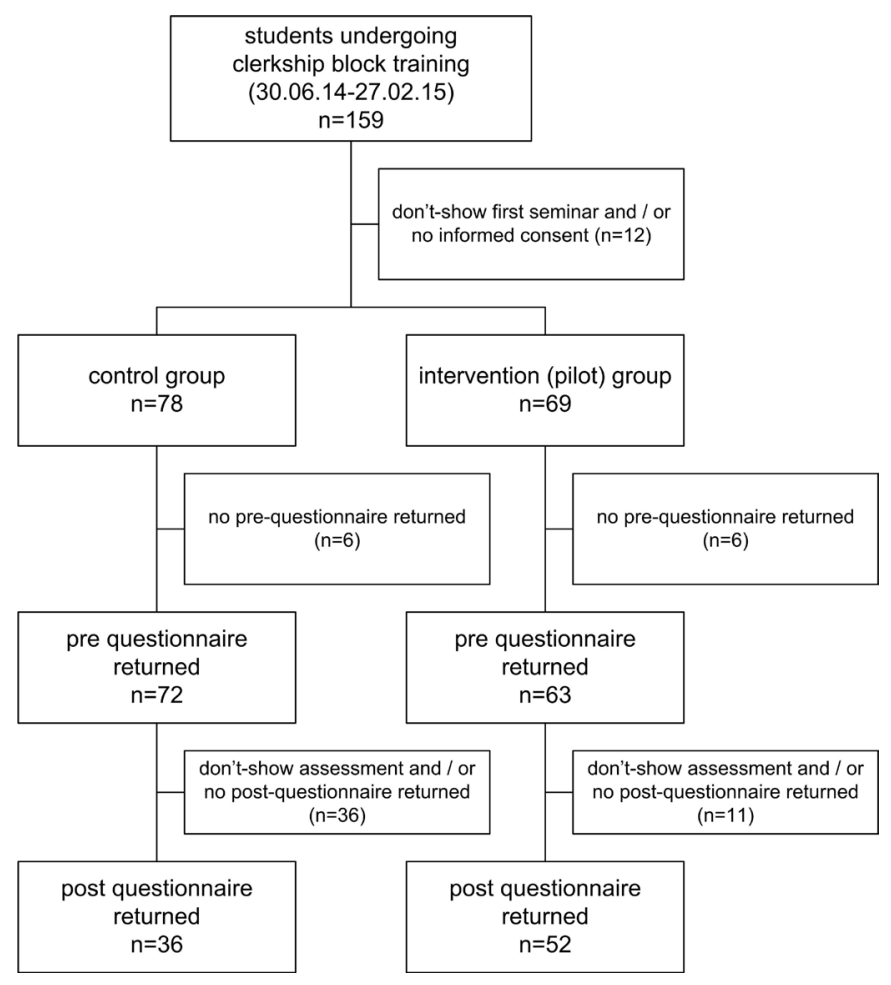

Figure 2 Flow chart participants and questionnaires.

\section{RESULTS}

Obtained outcome: awareness, confidence and knowledge of patient safety and handover in clinical practice

Demographic data of participants

From 159 students assigned to the course, 12 did not attend the first seminar module. One hundred and forty-seven students participated, the majority being female $(67 \%, n=99)$. Ninety-two percent $(n=135)$ of the pre-questionnaires and $60 \%(\mathrm{n}=88)$ of the post-questionnaires were returned (figure 2). Of the 69 students who participated in the pilot handover training, $91 \%$ returned the pre-questionnaires and $75 \%$ returned the post-questionnaires. In the control group $(n=78), 92 \%$ of the pre-questionnaires and $46 \%$ of the post-questionnaires were returned.

Some participants dropped out due to the non-mandatory nature of the modules and others declined to participate. Among the whole study population, $18 \%$ of the students (intervention group $n=14$, control group $\mathrm{n}=13$ ) had prior knowledge in nursing or emergency medical service. Forty-six percent $(n=67)$ of the students had been involved in more than 10 handovers during their clinical practice, while $35 \%(\mathrm{n}=51)$ indicated they had participated in less than five handovers.

\section{Attitudes}

Ninety-six percent of the students agree that a good medical handover is essential for patient safety (mean $=5.62, \mathrm{SD}=0.62$ ) and $70 \%$ admit that many adverse events happen due to communication errors (mean=5.02, $\mathrm{SD}=0.88)$. Forty-one percentdisagree that accurate handover cannot be taught (mean=2.91, 
Table 1 Pilot vs control group. ISOBAR, Identifiy, Situation, Observations, Background, Agreed Plan, Read Back; SBAR, Situation, Background, Assessment, Recommendation.

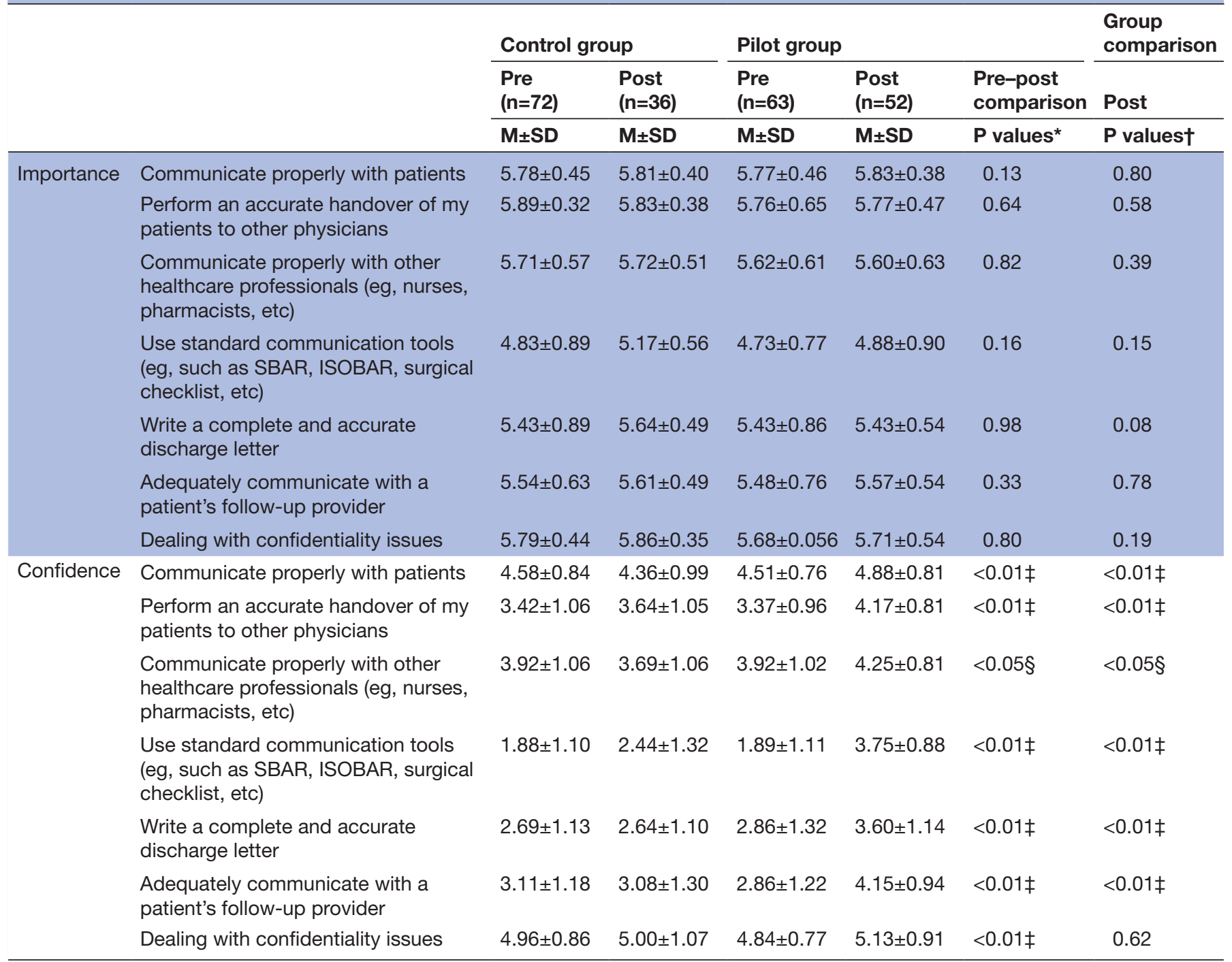

Scores are based on a 6-point Likert scale (1=not at all important/confident to 6=very important/confident).

*Wilcoxontest.

†Mann-Whitney test.

¥Significant at $1 \%$ level.

§Significant at $5 \%$ level.

$\mathrm{SD}=1.29)$ and $73 \%$ agree that the use of checklists is helpful (mean=4.99, $\mathrm{SD}=0.86)$.

\section{Awareness}

\section{Pre-evaluation}

The overall evaluation results of the pre-questionnaires are shown in table 1 . There were no detectable differences between the two groups $(p=0.22-0.98)$. The importance for using standardised checklists and communication tools was rated low compared with the other items. Only $67 \%$ rated the use of standard communication tools as important (mean $=4.78$, $\mathrm{SD}=0.84)$. The importance of proper communication with patients (mean $=5.78, \mathrm{SD}=0.45$ ) and accurate handover $($ mean $=5.83, \mathrm{SD}=0.50)$ were both rated high by $99 \%$ of the students. Correct discharge letter writing was also rated high by $92 \%$ (mean=5.43, $\mathrm{SD}=0.87$ ).

\section{Postevaluation}

After the AI course, awareness ratings were similar to the pre-evaluation. Overall, the importance for using standardised checklists and communication tools was marginally rated higher with $77 \%$ of agreement $(\mathrm{p}=0.05)$.

Comparing the two groups, there was no significant difference in the rating of importance of patient safety and handover, such as the importance of the use of standard communication tools $(\mathrm{p}=0.15)$, proper communication with patients $(\mathrm{p}=0.80)$, performing accurate handover $(\mathrm{p}=0.58)$ and writing a correct discharge letter $(\mathrm{p}=0.08)$. 


\section{Confidence}

\section{Pre-evaluation}

Only $11 \%$ of the students felt confident in performing an accurate handover (mean=3.39, $\mathrm{SD}=1.01)$. Students also lacked confidence in writing a complete and accurate discharge letter as only $9 \% \quad($ mean $=2.77, \mathrm{SD}=1.22)$ agreed to this item. Only $4 \%($ mean $=1.88, \mathrm{SD}=1.10)$ felt confident in using standardised checklists and communication tools. There were no detectable differences between the two groups $(p=0.17-0.96)$.

\section{Postevaluation}

After the AI course, the mean ratings for confidence in performing accurate handover increased for students of the pilot group from $3.37(\mathrm{SD}=0.96)$ to $4.17(\mathrm{SD}=0.81)$ $(\mathrm{p}<0.01)$. Compared with the students of the control group, this difference was significant (mean=3.64, $\mathrm{SD}=1.05 ; \mathrm{p}<0.01)$. Mean ratings for confidence in proper communication with patients was rated higher in the pilot group ( mean $_{\text {control }}=4.36, \mathrm{SD}=0.99 \mathrm{vs}$ meanpilot $=4.88, \mathrm{SD}=0.81 ; \mathrm{p}<0.01)$. Students of the pilot group also felt more confident in writing a complete and accurate discharge letter (mean $_{\text {control }}=2.64, \mathrm{SD}=1.10$ vs meanpilot $=3.60, \mathrm{SD}=1.14 ; \mathrm{p}<0.01)$.

The ratings of self-confidence improved in all aspects of communication and handover (see table 1): proper communication with patients $(\mathrm{p}<0.01)$, performing adequate handover $(\mathrm{p}<0.01)$, using standardised checklists and communication tools $(\mathrm{p}<0.01)$ and writing a correct discharge letter $(\mathrm{p}<0.01)$.

\section{Knowledge}

Pre-evaluation

Participants of both groups showed low knowledge prior to the handover teaching. On average, $52 \%$ of the questions were answered correctly, with no difference between the two study groups $(\mathrm{p}=0.90)$.

\section{Postevaluation}

After the AI course, participants of the pilot group had a significantly higher rate of correct answers than the participants of the control group $(\mathrm{p}<0.01)$ (figure 3$)$. Within the control group, there was no increase of knowledge $(\mathrm{p}=0.29)$, while in the pilot group the proportion of right answers increased significantly to $66 \%(\mathrm{p}<0.01)$.

\section{Course rating}

Handover training was rated as useful and important (mean=5.15, $\mathrm{SD}=1.04$ ). The overall course rating was obtained through the 6-point German grading scale (1=verygood, 6 =insufficient). The training intervention of the AI pilot curriculum was rated 'good' ( 2 on the 6 -point grading scale): anaesthesiology mean $=2.11, \quad \mathrm{SD}=0.92$; intensive care mean=2.41, $\mathrm{SD}=1.04$; emergency medicine mean $=1.6, \mathrm{SD}=0.75$.

\section{DISCUSSION}

The aim of this study was to implement and evaluate a newly developed standardised handover curriculum for medical students and to assess its effect on students' awareness, confidence and knowledge regarding handover in the context of patient safety. Overall, it was possible to implement and evaluate a pilot curriculum for standardised handover teaching of fourth-year medical students addressing multiple types of handover settings (end-of-shift, operating room/postanaesthesia recovery unit, ICU, telephone and discharge). A significant increase in knowledge and self-confidence for the use of standardised handover tools and accuracy in handover performance could be demonstrated.

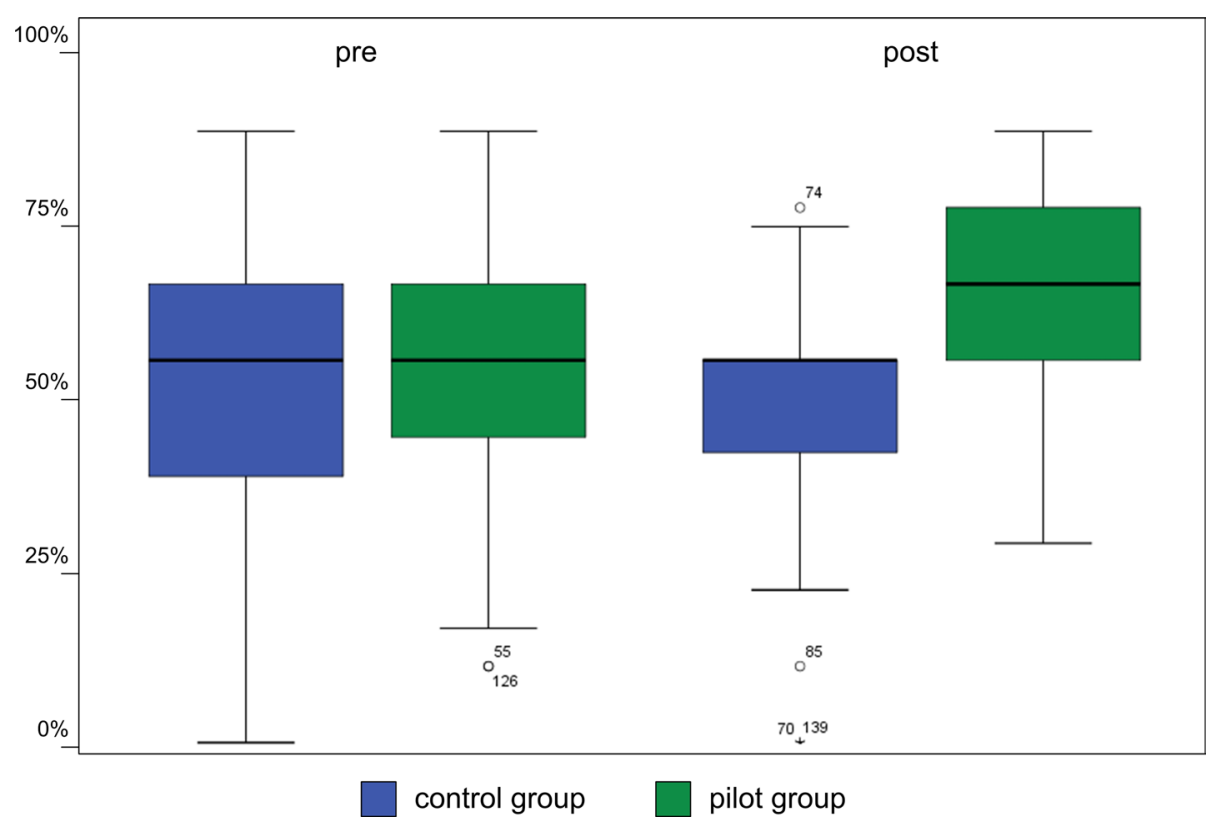

Figure 3 Correct answers of multiple-choice questions (\%): pilot vs control group. 
Before the implementation of the developed handover curriculum, nearly all of the students agreed that a good medical handover is essential for patient safety. The majority of the students recognised that many adverse events happen due to communication errors and agreed that the use of checklists is helpful. With respect to confidence in performing an accurate handover, in writing a complete and accurate discharge letter and in using standardised checklists and communication tools, very few students reported confidence. This situation is in line with previous published studies. ${ }^{20}$

The students' self-confidence and knowledge significantly changed after the handover teaching and training. This study's population's opinion that the use of checklists is helpful is also reflected in other literature proving that checklists and mnemonics are useful regarding handover. ${ }^{30-32}$ The use of a structured handover tool, like ISBAR, leads to a decrease in information omission and improves quality of handover, ${ }^{30} 3133$ especially in a deteriorating patient. ${ }^{32}$

Standardisation of handover together with improvement of communication skills and attitudes has also been shown to reduce adverse effects associated with handover ${ }^{6} 3034$ and possibly improve the patient's outcome. $^{53536}$

Therefore, implementation of a standardised handover curriculum with reasonable training methods and use of handover tools is essential. ${ }^{37}$ Considering undergraduate medical education, very little data exist regarding implementation and standardisation of handover processes, as most interventional studies over the past years have focused on residents. ${ }^{38}{ }^{39}$ Regarding the implementation of a handover curriculum, there is very little (controlled) data, especially in European medical education. ${ }^{14243940}$

In this study, students' awareness of patient safety in aspects of proper communication with patients and accurate handover as well as correct discharge letter writing was already high prior to any teaching intervention and did not significantly change afterwards. Students were aware that many adverse events happen due to errors in communication. In contrast to the increasing confidence for the use of standardised checklists and communication tools, the importance of using these was constantly rated low compared with the other items. The recognised upward trend for the control group was due to the illustration of the descriptive data of the whole preassessment cohort and can be regarded as negligible since no significant difference in inference statistical comparisons of repeated measured outcomes were found.

Overall, on the grading scale, the training intervention of the AI pilot curriculum was rated 'good'. Different course ratings may be due to the fact that the schedule of the 4-week AI clerkship is different for each clinical subject (see online supplementary file).

After receiving the pilot training curriculum, the students' knowledge improved and they were more confident at communicating with patients and performing verbal and written handovers, as well as using standardised communication tools. Furthermore, they rated handover training as useful and important. This again is in line with other studies in handover training for medical students. ${ }^{4041}$

This study reports a detailed description of the training interventions and the curriculum is available publicly as an open source. ${ }^{26}$ The curriculum on handover and patient safety ${ }^{27}$ is based on the results of a multi country European learning-needs analysis of medical students. ${ }^{22} 29$ It has been adapted based on the German results of the needs analysis at the medical school of RWTH Aachen University, and therefore, it meets the local students' needs. $^{22}$

The teaching modules of approximately 3 hours could easily be integrated into the existing course led by the Departments of Anesthesiology and Intensive Care Medicine. In these fields, the handover training addressed a variety of handover types. To meet different learning styles and learning motivations, the use of multiple educational methods had been considered. An accompanying online module made it possible for students to improve their knowledge regarding patient handover and to practice the writing of a discharge letter. Currently, long-term implementation of the curriculum has begun.

Published studies have shown improvement in knowledge and skills after different handover training interventions, as well as a recent reduction in errors and adverse events. ${ }^{42}$ With little effort, it is already possible to make a difference in students' performance and to raise awareness on patient safety at the early stage of medical training. Recently, a quasi-randomised controlled trial with thirdyear medical students showed a $30 \%$ improvement of handover performance after only a 1-hour interactive small group workshop. ${ }^{40}$ A needs analysis conducted in 2012 among European healthcare professionals raised the question, whether the standardisation of handover training was the right way to train healthcare providers. The authors concluded that 'one size does not fit all' in handover training. ${ }^{43}$ The adaptation of standardised handover tools thus remains a challenge, especially at large medical institutions. However, a recent study at a large medical centre proves that such challenges can be conquered. ${ }^{44}$

Common formats for workplace-based assessment, such as Mini-CEX (mini clinical examination) or DOPS (direct observed practical skill), may be a feasible way to continuously assess the performance of students as well as their learning progress with patient safety skills. ${ }^{45}$

\section{Limitations}

There are several limitations to this study. The curriculum was implemented in one single institution and the sample size was small. Students' needs for training might be different at other German medical schools. Also, data were based on subjective ratings, extracted from a composite survey, in which reliability and validity differed between subsections. Since participation was not mandatory, the students who returned questionnaires might have been 
more interested in or aware of the topic. We used paperbased cases for handover training, but comparable data suggests that good transfers can occur from the simulated setting to the clinical environment. ${ }^{40}$ Furthermore, the methodology of the study did not allow to distinguish, whether the improvement was more a result of the theoretical or the practical training, and how much the application of mnemonics influenced the recorded data. The authors can only assume that the mixed method curriculum is suitable for a group of different learner styles. An objective for future research is to also measure practical performance (eg, via video assessment).

\section{Conclusion}

A pilot curriculum for undergraduate handover training was implemented and evaluated at a large German medical faculty. Students displayed a significant increase in knowledge and self-confidence for the use of standardised handover tools and accuracy in handover performance.

The search for the best practice in handover training continues, but the first steps have been made in developing and implementing a new handover curriculum in undergraduate medical education in Germany. Further studies should include an evaluation of the implemented curriculum by other German medical schools and whether the observed effect is sustained across time and is associated with patient benefit. From a quality-improvement point, it remains unclear how much change can be induced by handover training at an early stage of medical education.

Acknowledgements We thank all students who contributed to this educational study. Furthermore, we thank our colleagues from the PATIENT-project team for their assistance and excellent work during the project.

Contributors LT and HS equally contributed to drafting this manuscript. LT, HS, LH, $\mathrm{JB}, \mathrm{PH}, \mathrm{RR}$ and SS have made substantial contributions to the design of the study, the analysis and interpretation of the; have been involved in editing the manuscript and have critically reviewed it for important intellectual content prior to submission; and have given final approval of the version submitted.

Funding The European Union Erasmus Multilateral Projects programme funded the PATIENT Project. Project number 527620-LLP-1-2012-1-NL-ERASMUS-FEXI.

Competing interests None declared.

Patient consent Not required.

Ethics approval Medical Ethics Committee, Medical Faculty, RWTH Aachen University (EK: 155/17).

Provenance and peer review Not commissioned; externally peer reviewed.

Data sharing statement Extra data can be accessed via the Dryad data repository at http://datadryad.org/withthedoi:10.5061/dryad.k602576.

Open access This is an open access article distributed in accordance with the Creative Commons Attribution Non Commercial (CC BY-NC 4.0) license, which permits others to distribute, remix, adapt, build upon this work non-commercially, and license their derivative works on different terms, provided the original work is properly cited, appropriate credit is given, any changes made indicated, and the use is non-commercial. See: http://creativecommons.org/licenses/by-nc/4.0/.

\section{REFERENCES}

1. The Joint Commission. Sentinel event statistics data - event type by year 1995-Q2-2016. Most commonly reviewed sentinel event types. Oakbrook Terrace, USA: The Joint Commission, 2016. https://www. jointcommission.org/sentinel_event.aspx (accessed 7 Jun 2017).
2. Joint Commission Center for Transforming Healthcare releases targeted solutions tool for hand-off communications. Jt Comm Perspect 2012;32:1-3.

3. Wong M, Yee K, Turner P. A structured evidence-based literature review regarding the effectiveness of improvement interventions in clinical handover. Australia: The eHealth Services Research Group, University of Tasmania for the Australian Commission on Safety and Quality in Health Care (ACSQHC), 2008. https://www. safetyandquality.gov.au/wp-content/uploads/2008/01/ClinicalHandover-Literature-Review-for-release.pdf (accessed 7 Jun 2017).

4. Segall N, Bonifacio AS, Schroeder RA, et al. Can we make postoperative patient handovers safer? A systematic review of the literature. Anesth Analg 2012;115:102-15.

5. Agarwal HS, Saville BR, Slayton JM, et al. Standardized postoperative handover process improves outcomes in the intensive care unit: a model for operational sustainability and improved team performance*. Crit Care Med 2012;40:2109-15.

6. Saager L, Hesler BD, You J, et al. Intraoperative transitions of anesthesia care and postoperative adverse outcomes. Anesthesiology 2014;121:695-706.

7. National Patient Safety Agency. Seven steps to patient safety: the full reference guide. London: The National Patient Safety Agency, 2004. http://www.nrls.npsa.nhs.uk/resources/collections/seven-steps-topatient-safety/?entryid45=59787 (accessed 7 Jun 2017).

8. Walton M, Woodward H, Van Staalduinen S, et al. The WHO patient safety curriculum guide for medical schools. Qual Saf Health Care 2010;19:542-6.

9. European Network for Patient Safety (EUNetPaS). A general guide for education and training in patient safety: EUNetPaS, 2010. http:// www.eu-patient.eu/globalassets/projects/eunetpas/guidelines_final_ 22-06-2010.pdf (accessed 6 Feb 2018).

10. The Patient Safety and Quality of Care Working Group1 (PSQCWG). Key findings and recommendations on education and training in patient safety across Europe Work of the Education and Training in Safety Patient Subgroup of the Patient Safety and Quality of Care Working Group of the European Commission: PSQCWG, 2014. https://ec.europa.eu/health//sites/health/files/patient_safety/docs/ guidelines_psqcwg_education_training_en.pdf (accessed 6 Feb 2018).

11. Aktionsbündnis Patientensicherheit e.V. (APS). Roads to patient safety: framework of learning goals for patient safety competencies. A Recommendation by Aktionsbündnis Patientensicherheit e.V. (APS) for organisations and teaching staff in the education and training of health care professionals. Berlin, Germany: APS Working Group for Education and Training, 2016. http://www.aps-ev.de/wp-content/ uploads/2017/03/Learning-Goals-1.pdf (accessed 6 Feb 2018).

12. Kiesewetter J, Gutmann J, Drossard S, et al. The learning objective catalogue for patient safety in undergraduate medical education-a position statement of the committee for patient safety and error management of the german association for medical education. GMS $J$ Med Educ 2016;33:Doc10.

13. MFT. Nationaler Kompetenzbasierter Lernzielkatalog Medizin (NKLM). Kiel, Germany: MFT Medizinischer Fakultätentag der Bundesrepublik Deutschland e. V., 2015. http://www.nklm.de/kataloge/nklm/lernziel/ uebersicht (accessed 7 Jun 2017).

14. Gordon M, Findley R. Educational interventions to improve handover in health care: a systematic review. Med Educ 2011;45:1081-9.

15. World Health Organization (WHO). WHO patient safety curriculum guide: multi-professional edition: WHO, 2011. http://apps.who. int/iris/bitstream/handle/10665/44641/9789241501958_eng.pdf; jsessionid=DE5F246634283E17D3C00FD48F65E810? sequence $=1$ (accessed 19 Apr 2018).

16. Dossow von V, Zwißler B. DGAlnfo, Empfehlung - Strukturierte Patientenübergabe in der perioperativen Phase - Das SBARKonzept. Anästh Intensivmed 2016;57:88-90.

17. Monsieurs KG, Nolan JP, Bossaert LL, et al. European resuscitation council guidelines for resuscitation 2015: section 1. Executive summary. Resuscitation 2015;95:1-80.

18. Liston BW, Tartaglia KM, Evans D, et al. Handoff practices in undergraduate medical education. J Gen Intern Med 2014;29:765-9.

19. Cleland JA, Ross S, Miller SC, et al. There is a chain of Chinese whispers: empirical data support the call to formally teach handover to prequalification doctors. Qual Saf Health Care 2009;18:267-71.

20. Monrouxe LV, Grundy L, Mann M, et al. How prepared are UK medical graduates for practice? A rapid review of the literature 20092014. BMJ Open 2017;7:e013656.

21. Institute of Medicine (US) Committee on Quality of Health Care in America. Crossing the quality chasm: a new health system for the 21st century. Washington (DC), US: National Academies Press, 2017.

22. Hynes $\mathrm{H}$, Stoyanov S, Drachsler H, et al. Designing learning outcomes for handoff teaching of medical students using group 
concept mapping: findings from a multicountry european study. Acad Med 2015;90:988-94.

23. Rosenthal JL, Doiron R, Haynes SC, et al. The effectiveness of standardized handoff tool interventions during inter- and intra-facility care transitions on patient-related outcomes: a systematic review. Am J Med Qual 2018;33:193-206.

24. McBryde M, Vandiver JW, Onysko M. Transitions of care in medical education: a compilation of effective teaching methods. Fam Med 2016;48:265-72.

25. Horwitz LI, Moin T, Green ML. Development and implementation of an oral sign-out skills curriculum. J Gen Intern Med 2007;22:1470-4.

26. PATIENT Project. Improving the continuity of patient care through novel teaching and learning facilities for handover procedures in medical higher education. Project Nr: 527620-LLP-1-2012-1-NLERASMUS-FEXI. http://patient-project.eu/ (accessed 7 Jun 2017).

27. Stieger L, Druener S, Schroeder H, et al. WP4 - Report: The PATIENT handover curriculum. Heerlen, The Netherlands: Patient Project, 2014. http://patient-project.eu/?page_id=1371 (accessed 7 Jun 2017)

28. Kern DE, Thomas PA, Hughes MT. Curriculum development for medical education: a six-step approach. 2nd edn. Baltimore, USA: The Johns Hopkins University Press, 2009.

29. Orrego C, Secanell M, Mora N, et al. WP2-deliverable: training needs analysis [public part]. Heerlen, The Netherlands: Patient Project, 2013. http://hdl.handle.net/1820/5218 (accessed 25 Jan 2018).

30. Starmer A, O'Toole J, Spector $\mathrm{N}$, et al. mentored implementation of the i-pass handoff program in diverse clinical environments. BMJ Qual Saf 2016;25:1009-10.

31. Salzwedel C, Mai V, Punke MA, et al. The effect of a checklist on the quality of patient handover from the operating room to the intensive care unit: a randomized controlled trial. J Crit Care 2016;32:170-4.

32. Dawson S, King L, Grantham H. Review article: improving the hospital clinical handover between paramedics and emergency department staff in the deteriorating patient. Emerg Med Australas 2013;25:393-405.

33. WHO Collaborating Centre for Patient Safety Solutions. Communication during Patient Hand-Overs. Geneva, Switzerland: World Health Organization (WHO), Patient Safety Solutions, Volume
1, Solution 3. 2007. http://www.who.int/patientsafety/solutions/ patientsafety/PS-Solution3.pdf?ua=1 (accessed 7 Jun 2017).

34. Francke AL, Smit MC, de Veer AJ, et al. Factors influencing the implementation of clinical guidelines for health care professionals: a systematic meta-review. BMC Med Inform Decis Mak 2008;8:38.

35. Breuer RK, Taicher B, Turner DA, et al. Standardizing postoperative PICU handovers improves handover metrics and patient outcomes. Pediatr Crit Care Med 2015;16:256-63.

36. Sutcliffe KM, Lewton E, Rosenthal MM. Communication failures: an insidious contributor to medical mishaps. Acad Med 2004;79:186-94.

37. Australian Medical Association. Safe handover - safe patients: guidance on clinical handover for clinicians and managers. Kingston, Australia: Australian Medical Association, 2006.

38. Horwitz LI, Moin T, Green ML. Development and implementation of an oral Sign-Out skills curriculum. J Gen Intern Med 2007;22:1470-4.

39. Riesenberg LA, Leitzsch J, Massucci JL, et al. Residents' and attending physicians' handoffs: a systematic review of the literature. Acad Med 2009;84:1775-87.

40. Reyes JA, Greenberg L, Amdur R, et al. Effect of handoff skills training for students during the medicine clerkship: a quasi-randomized study. Adv Health Sci Educ Theory Pract 2016;21:163-73.

41. Gaffney S, Farnan JM, Hirsch K, et al. The Modified, Multi-patient Observed Simulated Handoff Experience (M-OSHE): Assessment and Feedback for Entering Residents on Handoff Performance. $J$ Gen Intern Med 2016;31:438-41.

42. Starmer AJ, Spector ND, Srivastava R, et al. Changes in medical errors after implementation of a handoff program. N Engl J Med 2014;371:1803-12.

43. Kicken W, Van der Klink M, Barach P, et al. Handover training: does one size fit all? The merits of mass customisation. BMJ Qual Saf 2012;21(Suppl 1):i84-i88.

44. Shahian DM, McEachern K, Rossi L, et al. Large-scale implementation of the I-PASS handover system at an academic medical centre. BMJ Qual Saf 2017;26:760-70.

45. Farnan JM, Paro JA, Rodriguez RM, et al. Hand-off education and evaluation: piloting the observed simulated hand-off experience (OSHE). J Gen Intern Med 2010;25:129-34. 